\title{
A RADIODIFUSÃO ABERTA E A DEMOCRATIZAÇÃO DA COMUNICAÇÃO NO LULISMO: HEGEMONIA DOS ÇORONÉIS ELETRÔNICOS
}

\author{
THE OPEN BROADCASTING AND THE DEMOCRATIZATION OF \\ COMMUNICATION IN LULISM: HEGEMONY OF ELECTRONIC \\ COLONELS
}

\author{
LA RADIODIFUSIÓN ABIERTA E LA DEMOCRATIZACIÓN EN LO \\ LULISMO: HEGEMONÍA DE LOS CORONELES ELECTRÓNICOS
}

\author{
Rafael Bellan Rodrigues de Souza \\ Jornalista e docente da \\ Universidade Federal do \\ Amazonas (UFAM), campus de \\ Parintins \\ rafaelbellan@yahoo.com.br
}

\section{Resumo}

Com base em uma perspectiva crítica ontológica do fenômeno político do lulismo, busca-se demonstrar como nas últimas décadas os debates em torno da regulação da radiodifusão aberta foi hegemoniza pelo coronelismo eletrônico. Partindo de um debate histórico sobre o patrimonialismo e clientelismo resultantes da modernização, pelo alto, da sociedade brasileira, evidencia-se a continuidade dos governos petistas na defesa do bloco histórico dominante, demarcado principalmente pela sua evidente fragilidade em abraçar a pauta da democratização da comunicação.

Palavras-chave: Radiodifusão. Lulismo. Hegemonia.

\begin{abstract}
Based on an ontological critical perspective of politician phenomenon lulism, we seek to demonstrate how in the last decades the debate on the regulation of broadcasting was led by the hegemonic electronic colonelism. From a historical debate about patronage and clientelism resulting from modernization, over the top, of Brazilian society, highlights the continuity of PT governments in defending the dominant historical bloc, marked mainly by its apparent fragility to embrace the agenda of the democratization of communication.
\end{abstract}

Keywords: Broadcasting. Lulism. Hegemony.

\section{Resumen}

Sobre la base de una perspectiva crítica ontológica de lo fenómeno político del lulismo, buscamos demostrar cómo en las últimas décadas el debate sobre la regulación de la radiodifusión fue inaugurado por el hegemonía de lo coronelismo electrónico. Desde un debate histórico sobre patronazgo y clientelismo que resulta de la modernización de la 
sociedad brasileña, destaca-se la continuidad de los gobiernos del PT en la defensa del bloque histórico dominante, marcada sobre todo por su aparente fragilidad de abrazar la agenda de la democratización de la comunicación.

Palabras clave: Radiodifusión. Lulismo. Hegemonía.

\section{INTRODUÇÃO}

Os meios de comunicação brasileiros possuem como característica principal uma progressiva e contínua centralização nas mãos do poder hegemônico. Mesmo com o advento das chamadas mídias digitais, parte de uma reestruturação no ecossistema midiático que notadamente potencializa novos sujeitos comunicantes, a "velha mídia" permanece um latifúndio midiático intocado, visto que uma democratização ampla da radiodifusão tem sido uma pauta praticamente ignorada pelo Estado. Resquício de uma modernização realizada pelo alto, a sociedade brasileira carrega o estigma do patrimonialismo, clientelismo e do poder econômico no centro de sua democracia e, assim, a comunicação, que no limite é a própria esfera em que a política se realiza, permanece sendo dirigida pelo bloco histórico dominante.

Isso não é surpreendente se pensarmos o papel dos meios de comunicação na constituição das visões de mundo dos sujeitos sociais, cuja centralidade ainda faz-se presente. Os tímidos avanços na regulamentação do setor têm derrotado as perspectivas dos coletivos, movimentos sociais e organizações que lutam em prol da efetivação do direito humano à comunicação - o que significa não apenas atuar como consumidor passivo de bens culturais, mas como protagonista, produtor, organizador dos sentidos expressos na totalidade social.

O protagonismo da mídia na formação de concepções de mundo, sentidos e expressões, visões políticas e rearticulações culturais, colocam-na um papel de destaque na construção de realidades que rearticulam/transmitem/elaboram um conjunto de referências ligadas a uma direção moral e intelectual da sociedade, ou seja, hegemonia. A imprensa e a própria mídia se concretizam na esteira daquilo que Gramsci (1999) delimita como aparelho privado de hegemonia, ou seja, aparelhos utilizados como produtores e transmissores de ideologias. Eles são esferas da sociedade civil que promulgam o consenso como eixo orgânico e auxiliar do poder de coerção do Estado, em seu sentido ampliado.

Demonstraremos que o período lulista (que compreende a gestão do Estado de 2002 até os dias atuais) ao se direcionar a um pacto com as elites conservadoras e buscar uma quimérica síntese entre capital e trabalho, também sucumbe ao poder dos coronéis eletrônicos, 
frustrando a corrente progressista que confiou, talvez com certa dose de simpatia, esperanças de avanços reformistas num governo assentado ao modelo estrutural de Estado burguês.

\section{CONCENTRAÇÃO MIDIÁTICA: UMA QUESTÃO SÓCIO-HISTÓRICA}

A radiodifusão, conforme a legislação brasileira, congrega os serviços de informação destinados a serem recebidos direta e livremente pelo público em geral e divide-se em radiodifusão sonora (rádio) e radiodifusão de sons e imagens (televisão). Ela constitui o segmento economicamente mais importante dos sistemas de comunicação no Brasil: representa cerca de $2 / 3$ de todo o mercado de mídia. Tradicionalmente chamados de comunicação de massa, os produtos de radiodifusão aberta utilizam-se do espectro eletromagnético e, portanto, não possuem proprietários, mas concessionários.

Segundo Lima (2011) podemos mapear algumas características gerais da mídia brasileira, sendo que a primeira delas é o modelo de exploração da radiodifusão que privilegia, quase de forma total, a atividade privada comercial. Essa opção é resultado de decisões tomadas ainda na década de 30 do século passado, em um modelo de curadoria que se origina nos Estados Unidos: a União explora o serviço, terceirizando sua administração para a iniciativa privada. Outro ponto relevante de nossa mídia é a quase total ausência de regulação, visto que não se enfrenta de forma clara a propriedade cruzada dos meios, ou seja, que o mesmo grupo empresarial tenha concessões de rádio, televisão, e ainda jornais impressos. A consequência direta dessa flexibilidade legal, e ausência de obediência aos parcos decretos que poderiam coibir tal prática, é a oligopolização da mídia privada, criadora dos "barões de mídia", cujas ações expressam o chamado coronelismo eletrônico. Entre os personagens dessa concentração, podemos citar as oligarquias políticas e familiares e também as Igrejas, que avançam cada dia mais no controle dos meios de comunicação. Em nosso sistema midiático de radiodifusão destaca-se a hegemonia de um grande e único grupo privado, as Organizações Globo, que abocanham a gulosa fatia de sessenta por cento da publicidade nacional, sendo líder de audiência do segmento de televisão.

Pode-se afirmar, portanto, que, quando se trata da radiodifusão e da imprensa, nos antecipamos à tendência de concentração da propriedade na mídia manifestada pelo recente processo de globalização. A propriedade entre nós sempre foi concentrada e, ademais, concentrada dentro dos parâmetros inexistentes em outros países (LIMA, 2011, p.30).

Nesse sentido, um dos aspectos mais destacados da comunicação no Brasil é a tendência para a oligopolização dos meios. A concentração midiática no Brasil ocorre em três 
níveis: da propriedade, da audiência e da distribuição da verba publicitária pelas agências (SOARES, 2006). Isso traz um grave problema para qualquer visão democrática, pois,

Quanto maior a concentração dos meios de comunicação, menor a quantidade de grupos que podem ter acesso a eles, resultando na redução virtual da liberdade de expressão da sociedade, cujo exercício efetivo fica restrito às famílias detentoras dos oligopólios de meios existentes. No entanto, todas as vezes que se discute a necessidade de regulamentação das comunicações, os empresários do setor se defendem com o argumento de ameaças de restrições à liberdade de expressão, de censura dos meios, recusando a discussão (SOARES, 2006, p.125).

No contexto da chamada “era Vargas", em 1931, é dada a largada da tradição brasileira de o governante em exercício fazer concessões de canais de radiodifusão aos seus aliados e simpatizantes políticos, usando o poder comunicativo como moeda política (ALMEIDA, 1971 apud SOARES, 2006). A televisão, cujas transmissões tiveram início em 1954, se desenvolveu seguindo o modelo já traçado pelo rádio, como concessão a título precário outorgada pelo presidente da República.

As políticas democráticas de comunicação só vieram a ser discutidas na década de 1980, quando os modelos operacionais já estavam consolidados, os canais concedidos e os meios já solidamente estabelecidos, sob a forma de empresas e redes poderosas e influentes (SOARES, 2006, p.120).

O latifúndio comunicativo segue uma espécie de paradigma patrimonialista brasileiro, iniciado muito tempo antes do advento dos meios de comunicação de massa como nós os conhecemos. No período da República Velha, a estrutura agrária concentrada permitia controle político, pois com uma população majoritariamente rural, o poder da propriedade transfigurava-se em poder político. O controle do voto era feito pelos grandes proprietários de terra. Leal (1986) explicita no conceito de "coronelismo" a troca de favores entre o poder público e os proprietários de terras, um tipo de dominação política clientelista que se tornara a tônica da vida republicana.

Qualquer que seja, entretanto, o chefe municipal, o elemento primário desse tipo de liderança é o "coronel", que comanda discricionariamente um lote considerável de votos de cabresto. A força eleitoral empresta-lhe prestígio político, natural coroamento de sua privilegiada situação econômica e social de dono de terras. Dentro da esfera própria de influência, o "coronel" como que resume em sua pessoa, sem substituí-las, importantes instituições sociais. Exerce, por exemplo, uma ampla jurisdição sobre seus dependentes, compondo rixas e desavenças e proferindo, às vezes, verdadeiros arbitramentos, que os interessados respeitam (p.24).

Os velhos coronéis controlavam o voto e como pagamento por esse serviço deliberavam sobre o orçamento, indicavam cargos, e mantinham um poder muito forte sobre as políticas públicas do município. Já o coronelismo eletrônico é um fenômeno da segunda 
metade do século XX. Resulta da adoção do sistema de outorga de serviços públicos de rádio e televisão para exploração de empresas privadas. Esse novo coronel promove a si mesmo e aos seus aliados, combate seus adversários e tenta direcionar a opinião pública a seu favor. A barganha política ainda se expressa pelo voto, só que não mais pautado na posse da terra, mas no controle da informação.

Santos e Capparelli (2005) consideram o coronelismo eletrônico uma forma de clientelismo entre os detentores do poder político e os proprietários de canais de televisão. Isso bloqueia a diversidade na radiodifusão aberta, priorizando os interesses particulares em detrimento do interesse público. As outorgas controladas por políticos computam 33,6\%, ou seja, elas são propriedade de pessoas que exercem ou exerceram mandato eleitoral. No Brasil é comum a prática de o outorgante ser o próprio concessionário, ou quando não explicitamente, são seus familiares os proprietários de empresas de rádio e televisão.

Com a municipalização proposta pela Constituição de 88 , surge um coronelismo complementar ao eletrônico, focado nas permissões e autorizações locais de radiodifusão (LIMA, 2011). Essas concessões referem-se às retransmissoras (RTV), às emissoras de rádio FM e comunitárias legalizadas. Esse coronelismo de novo tipo atinge os municípios, que se fortalecem como entes federativos. A troca política se dá com o uso das concessões de radiodifusão como moeda.

Havia uma expectativa de que a nova Constituição brasileira fosse um instrumento capaz de levar a uma ampla democratização da comunicação social. Muitas propostas inovadoras eram encaminhadas às subcomissões preparatórias dos textos para debate no plenário da Assembleia Nacional Constituinte. Contudo, ao final de meses de discussão, os deputados ligados aos meios de comunicação derrubaram o relatório apresentado nesses debates preliminares. A comissão de Comunicação foi a única a não ter um documento para encaminhar ao plenário da Constituinte. A constituição atribui um poder maior aos municípios e soma o Congresso nacional na concessão de radiodifusão, promovendo o coronelismo de novo tipo.

Todavia, é inegável que certas pautas dos movimentos sociais pela democratização foram adicionadas na Constituição de 88, como: a proibição de restrições à manifestação do pensamento, à criação, à expressão e à informação; a proibição de monopólios e oligopólios de meios de comunicação social; a regionalização da produção cultural, artística e jornalística; a criação do Conselho de Comunicação Social, ligado ao Senado Federal, com participação de representantes da sociedade... Não obstante, a ausência de regulamentação desses itens frustrou o clamor dos movimentos sociais. 
A hegemonia da "bancada" dos coronéis eletrônicos possuía muita força no período da constituinte, colocando o interesse privado em destaque e fragilizando a compreensão da ideia da comunicação ser regulamentada como um serviço público. A conjuntura foi amplamente favorável aos coronéis eletrônicos: aprovação das concessões de 10 anos para rádio e 15 anos para TV; a renovação praticamente automática dessas concessões; a programação desses veículos não passa por uma cuidadosa avaliação, embora existam os critérios; os meios não podem ser alvo de oligopólio e monopólio, mas na realidade são; os congressistas são os próprios concessionários (coronelismo eletrônico); existe a duplicidade de outorgas (fora da fiscalização pública); há uma total falta de fiscalização sobre a transferência de outorga. Enfim, predominou, e ainda predomina, a defesa de velhos interesses, sempre encoberta por uma fachada democrática.

O coronelismo de novo tipo consegue, a partir da redemocratização, abocanhar o filão das rádios comunitárias. Lima (2011) atesta que de 2205 rádios investigadas por ele, 1106 possuem vínculos com políticos.

Na trajetória do movimento de democratização, observa-se, por conseguinte um padrão: o establishment da radiodifusão manteve-se imponderável em face das lutas, revelou a capacidade de perpetuar-se inalterável, mantendo a posição dos grupos proprietários (SOARES, 2006, p.136).

Buscar as causas desse padrão, visto por alguns teóricos governistas como herança maldita, força-nos a investigar suas causas mais profundas e, nesse sentido, é impossível não relacionarmos essa centralização oligopólica da mídia ao desenho de formação e constituição do Estado brasileiro. Afinal, a trama da política de comunicações no Brasil é decorrente dos avanços e retrocessos da luta de classes no país, do desenvolvimento das forças produtivas, das contradições sociais que, em um movimento de continuidade e também descontinuidade, modela a conjuntura dessa hegemonia dos coronéis eletrônicos, parte do poder econômico imperante.

Desde que se proponham o "desenvolvimento" e a "revolução dentro da ordem" que são compatíveis com o capitalismo dependente, as classes burguesas buscam a única revolução nacional por que podem lutar em tais condições, a qual consiste em consolidar o poder burguês através do fortalecimento das estruturas e funções nacionais de sua dominação de classe. O que entra em jogo, portanto, não são as compulsões autoritárias (por mais formais e abstratas que sejam) de uma comunidade política nacional, mais ou menos complexa e heterogênea. Mas o alcance dentro do qual certos interesses especificamente de classe podem ser universalizados, impostos por mediação do Estado a toda a comunidade nacional e tratados como se fossem "os interesses da nação como um todo" (FERNANDES, 2006, p.350). 
A via de desenvolvimento do nosso sistema sócio-político foi caracterizada por vários intelectuais críticos, entre eles Florestan Fernandes (2006) e Caio Prado Júnior (2006), como um processo em que as classes dominantes conseguem, cooptando e dirigindo os processos sociais, calar as demandas das classes subalternas. Pinassi (2009) delineia essa dinâmica como uma espécie de prussianismo colonial, ou seja, além de tardio e antidemocrático, os traços da modernização brasileira situam-se nos marcos da periferia do sistema de reprodução do capital. A hipótese da revolução passiva permanece como tônica dessa reflexão.

(...) o Brasil se modernizou "pelo alto", prussianamente, passivamente, gerando com isso formas extremamente perversas de desigualdade social, tremendos déficits de cidadania. Mas o fato é que, malgrado isso, nosso país se modernizou, tornou-se o que Gramsci chamaria de uma "sociedade ocidental". E isso nos obriga a fazer novas reflexões e desafios teóricos. Por exemplo, a darmos conta de formas mais sofisticadas de dominação burguesa, como aquelas que vigoram hoje, quando ela se expressa por meio dos governos de um ex-intelectual e de um ex-líder sindical (COUTINHO, 2007, p.135)

Nesse ínterim, acreditamos que as políticas de comunicação no governo petista não abalaram e não desafiam, substantivamente, o poder do bloco histórico dominante, em especial os coronéis tradicionais, eletrônicos, ou eletrônicos de novo tipo, ainda que, suavemente, algumas concessões sejam dadas à participação da sociedade civil nos processos de debate sobre a questão. No entanto, as derrotas na democratização da radiodifusão demonstram que, nesse setor, o poder centralizado da mídia permanece inabalado.

\section{O LULISMO E A COMUNICAÇÃO}

Com a vitória presidencial de Luís Inácio Lula da Silva, grande parte dos movimentos dos trabalhadores foi atraída pela política do PT. Proposto como um governo de "coalizão", os petistas governistas tem perseguido uma linha de submissão ao capitalismo internacional, norteado pela ampliação da exportação de commodities e na intensificação do modelo neoliberal. Depositário da esperança dos trabalhadores de que seria organização protagonista da desintegração do neoliberalismo no Brasil, o PT converte-se em instrumento da afirmação do capital em nosso território, sendo o novo gestor dos interesses de parte da classe dominante brasileira. Com uma base composta por tradicionais setores da direita, que mantém nas mãos a política econômica, o governo convergiu dois aspectos da barbárie brasileira:

(...) sua política remunerou como nenhuma outra as diversas frações burguesas e, no extremo oposto da pirâmide social, onde encontramos os setores mais desorganizados e empobrecidos da população brasileira, que dependem das doações do Estado para sobreviver, ofereceu uma política 
assistencial, sem tocar sequer minimamente em nenhum dos dois pilares estruturantes da tragédia brasileira (ANTUNES, 2011, p. 146-147).

A política assistencial do projeto lulista, que agrada os estratos sociais mais "carentes" relaciona-se contraditoriamente com a política econômica, pautada no incentivo do capital financeiro, que enriquece cada dia mais não só banqueiros, mas também a burguesia industrial e os fazendeiros do agronegócio (ou latifúndio, as diferenças são cosméticas), agraciados com a ampliação de seus ganhos. O Programa de Aceleração do Crescimento (PAC), que teve na lulista Dilma Roussef sua coroação, beneficia os setores produtivos, injetando recurso público no ramo industrial, realçando uma perspectiva desenvolvimentista que sofre resistência das comunidades tradicionais (caso das tragédias ambientais anunciadas pela Usina Hidrelétrica de Belo Monte e pela transposição do Rio São Francisco, entre outras).

Com o objetivo de humanizar o capitalismo, arrebatando setores sindicais, compensados por fundos de pensão e cargos públicos (principalmente CUT e Força Sindical), o arrojado aparato do PT no governo, criado por uma figura popular ${ }^{1}$, que fala a "língua" do povo, cria uma nova forma de política: o lulismo, atualmente, em sua essência, seguido à risca por Dilma Rousseff. Camuflada com doses ampliadas de populismo, a figuração em torno da defesa dos trabalhadores oculta um perfil favorável ao desenvolvimento do capital.

Ao contrário do que sugerem as aparências, o governo Lula, independentemente de suas intenções, acentuou, em vez de diminuir, as características fascistóides do Estado brasileiro. Vivemos a barbárie em nosso cotidiano, mas estamos contentes com o carro novo, a televisão de 42 polegadas e a última versão do iphone. E, secretamente, até acreditamos que o futuro imediato do Brasil é brilhante. A coisa vai muito mal (ARBEX JR., 2011, p. 6).

Da criminalização dos movimentos sociais e indígenas, das violências cometidas contra mulheres, negros, e crianças, da destruição dos direitos históricos das classes subalternas, há uma hegemonia em torno de um projeto que, agraciando a burguesia externa e interna, exerce controle sobre grande parte dos trabalhadores formais e precarizados, compensando-os com linhas de crédito, incentivando-os ao consumo e consequente a um vultuoso endividamento junto aos bancos.

Para Pinassi (2011), o lulismo seria expressão da maioridade burguesa da política atingida pelo Estado brasileiro. Ele

(...) faz a mediação entre os interesses do grande capital e os produtos mais incontornáveis do padrão de acumulação imposto: desemprego estrutural,

\footnotetext{
${ }^{1}$ Para Antunes (2011), há um certo resgate do getulismo em Lula, principalmente na empatia deste com a massa depauperada.
} 
fome e destruição ambiental. O seu prestígio vem, principalmente, do fato de fazer tudo isso sem provocar qualquer mudança substantiva ao país historicamente marcado pela condição de colonialidade crônica, de desigualdade social endêmica, de debilidade - até aqui não-superada - de sua posição pífia no ranking do mercado de bens de produção, de sua inferioridade na geração de tecnologias, da permanente instabilidade da sua economia e política internas (p. 108).

No setor das comunicações, em especial a radiodifusão, as derrotas dos setores populares e coletivos que lutam pela democratização da mídia são nítidas. Lima (2011) aponta os revezes da luta pela democratização contra o poder dos coronéis no período Lula. Um primeiro caso explorado por ele é a tentativa de criação de um Conselho Federal dos Jornalistas; encaminhado em 2004 e amplamente debatido entre a categoria, a proposta visava um maior controle ético da profissão e foi rejeitado pela Câmara após a oposição violenta da grande mídia. O mesmo ocorreu após o incomodo gerado pelo Cadastro Geral dos concessionários de radiodifusão de autoria do Deputado Miro Teixeira, que mapeava os nomes dos coronéis eletrônicos brasileiros. A transparência proposta foi enevoada no início de 2007 e, agora, quem quiser descobrir o nome dos proprietários de emissoras de radiodifusão tem que garimpar a informação no site da Anatel. Outro exemplo de derrota das classes subalternas e de um setor em que o governo foi incapaz de levantar uma bandeira progressista é a inoperância em torno das rádios comunitárias. Pelo contrário, o governo intensificou a repressão aos veículos livres, acusados de ilegais em um processo de criminalização ainda longe de ser superado. Já a criação da Empresa Brasil de Comunicação foi vista como um avanço, dado que representa uma televisão pública no ar, mas ainda faltam avaliações que demonstrem seu papel na produção de um conteúdo diferente das comerciais, principalmente no tocante ao seu papel educativo e transformador.

Um marco nessa questão foi a tentativa de realização de um amplo debate social em torno da comunicação e sua regulamentação. A I Conferência Nacional de Comunicação (CONFECOM), contudo, foi abandonada por várias entidades empresariais como a Associação Brasileira de Emissoras de Rádio e Televisão (ABERT). Mesmo assim, sua realização em dezembro de 2009 foi garantida e apresentou propostas de regulação do setor de comunicações. Só que o lobby das "patronais" da radiodifusão permaneceu uma força que colocou na reserva os avanços da Conferência, que juntou a soma expressiva de mais de 1600 delegados eleitos no Brasil todo.

Outro caso paradigmático dos recuos do lulismo frente às bandeiras progressistas na área da radiodifusão são as mudanças realizadas no III Programa Nacional de Direitos Humanos (PNDH3) cujo item de direito à comunicação foi propagandeado como ameaça à 
liberdade de expressão, fazendo com que os coronéis eletrônicos articulassem um relatório final quase inofensivo ao seu poderio.

A chegada da televisão digital renovou o ímpeto da mobilização das entidades por mudanças na radiodifusão. Essa tecnologia implica uma transformação radical das transmissões de TV, permitindo a multiplicação do número de canais disponíveis, a TV de alta definição, interatividade, entre outras características. As políticas de comunicação relacionadas à TV digital passaram a ser alvo de disputas entre a sociedade civil organizada (BOLAÑO, 2007). A possibilidade de abertura do espectro para uso de mais grupos (algo que permitiria uma maior diversidade de canais e novos protagonistas atuando nas comunicações) esbarrou no interesse corporativo dos empresários do ramo. O ano de 2006 foi decisivo e o ministro Hélio Costa, representante dos interesses dos concessionários de radiodifusão, decide por um modelo concentracionista. Ao lograrem a manutenção de $6 \mathrm{MHz}$, as redes mantêm a posse do espectro eletromagnético como usucapião, ou seja, direito adquirido (SOARES, 2006).

Esse breve panorama ilustra a manutenção da concentração midiática na radiodifusão no período lulista. É perceptível que, nos poucos momentos históricos em que se pautou a regulação mais radical dos meios, o poder midiático rapidamente mostrou sua força, colocando o governo em uma posição servil. Por não abalar a estrutura do Estado em favor de uma mudança mais substantiva e também por se adequar ao modelo hegemônico de constituição do papel da democracia na sociedade brasileira, o lulismo como forma de governo acentuou uma esquizofrenia extremamente letal aos movimentos sociais que lutam pela democratização da comunicação, pois, ao mesmo tempo em que os aproxima da esfera estatal, engessa a combatividade desses sujeitos coletivos.

O surpreendente é que, principalmente na segunda eleição de Dilma e, mais recentemente na questão da corrupção na Petrobrás, os grandes proprietários da mídia massiva - mesmo agraciados com a inépcia das políticas de radiodifusão do governo - tentam, como partidos políticos que se tornaram (LIMA, 2004), demonstrar a falência do neodesenvolvimentismo lulista.

\section{CONSIDERAÇÕES}

O modelo de radiodifusão aberta manteve-se sem abalos em face das lutas, revelou a capacidade de perpetuar-se inalterável, mantendo a posição dos grupos proprietários. Como aparelho privado de hegemonia, esses meios de comunicação são esferas que compartilham 
com o Estado o poder de expressar a direção moral e intelectual que a sociedade segue. Parte da hegemonia, e com uma centralidade ainda muito forte no agendamento e no cultivo de visões de mundo, as emissoras de rádio e televisão ditam, com certa dose de cinismo, os rumos da economia, da política e cimentam o caminho da dominação de classe.

A luta contra-hegemônica pela democratização da comunicação, questionando a grande concentração do poder político brasileiro, contrário a qualquer mudança, aponta que democratizar os meios é lutar para democratizar a sociedade como um todo. Sem um sujeito coletivo capaz de romper com as amarras do sistema midiático, parte do sóciometabolismo do capital (MÉSZÁROS, 2007), não há esperanças de avanços no modelo lulista. Pelo contrário, com a ampliação do escopo das pautas dos empresários e dos setores conservadores da base aliada de Dilma Roussef, o que se avizinha são mais golpes à classe trabalhadora e suas demandas. O problema é prático: avançar nas lutas sociais e romper com a ordem econômica e política. Os avanços não necessariamente surgirão nas ruas, mas nos movimentos capazes de debater e instituir rupturas sistêmicas para além do capitalismo.

\section{REFERÊNCIAS}

ANTUNES, Ricardo. O continente do labor. São Paulo: Editora Boitempo, 2011.

ARBEX JR., José. Lula e o cordial "fascismo à brasileira". Caros Amigos, São Paulo, $\mathrm{n}^{\circ}$ 161, p. 6-7, agosto, 2011.

BOLAÑO, César Ricardo Teixeira. Qual a lógica das políticas de comunicação no Brasil? São Paulo: Paulus, 2007.

COUTINHO, Carlos Nelson. O marxismo no Brasil. In: JINKINGS, Ivana e PESCHANSKI, Alexandre (Orgs). As utopias de Michel Löwy. São Paulo: Boitempo, 2007.

FERNANDES, Florestan. A Revolução Burguesa no Brasil: ensaio de interpretação sociológica. São Paulo: Globo, 2006.

GRAMSCI, Antonio. Cadernos do cárcere, V.1. São Paulo: Civilização Brasileira, 1999.

GRAMSCI, Antonio. Poder, política e partido. (Org) SADER, Emir. São Paulo: Expressão popular, 2005.

LEAL, Victor Nunes. Coronelismo, Enxada e Voto. São Paulo: Editora Alfa-Ômega, 1986.

LIMA, Venício A. de. Mídia: teoria e política. São Paulo: Fundação Perseu Abramo, 2004.

LIMA, Venício Artur de. Regulação das comunicações: história, poder e direitos. São Paulo: Paulus, 2011. 
MÉSZÁROS, István. O desafio e o fardo do tempo histórico. São Paulo: Boitempo Editorial, 2007.

PINASSI, Maria Orlanda. Da miséria ideológica à crise do capital. São Paulo: Boitempo Editorial, 2009.

PINASSI, Maria Orlanda. O lulismo, os movimentos sociais no Brasil e o lugar social da política. Revista Lutas Sociais, São Paulo, no $25-26$, p.105-120, $2^{\circ}$ semestre de 2010 e $1^{\circ}$ semestre de 2011.

PRADO JR., Caio. História Econômica do Brasil. São Paulo: Brasiliense, 2006.

SANTOS, Suzy; CAPPARELLI, Sérgio. Coronelismo, radiodifusão e voto: a nova face de um velho conceito In: BRITTOS, Valério Cruz; BOLAÑO, César Ricardo Siqueira (orgs.). Rede Globo: 40 anos de poder e hegemonia.1 ed. São Paulo: Paulus, 2005.

SOARES, Murilo Cesar. A luta pela democratização dos meios e as tecnologias digitais. Revista Comunicação midiática, número 5. Bauru, SP: Unesp, 2006.

Original recebido em: 04/06/2015

Aceito para publicação em: 04/11/2015

Rafael Bellan Rodrigues de Souza Professor adjunto do curso de Comunicação Social/Jornalismo do Instituto de Ciências Sociais, Educação e Zootecnia (ICSEZ) da Universidade Federal do Amazonas (UFAM), em Parintins (AM). Possui doutorado em Ciências Sociais pela Universidade Estadual Paulista Júlio de Mesquita Filho (Unesp), mestrado em Comunicação Midiática pela Unesp (2006) e graduação em Comunicação Social - Jornalismo também pela Unesp (2003). Lidera o Grupo de Pesquisa Estudos Sociais Interdisciplinares do Baixo Amazonas. Tem experiência nas áreas de Comunicação, Jornalismo e Sociologia, atuando principalmente nos seguintes temas: mídia, comunicação alternativa, ideologia, teoria e ética do jornalismo, produção de sentido, marxismo e movimentos sociais.

Esta obra está licenciada sob uma Licença Creative Commons 